\title{
Efficacy of tamsulosin and silodosin as medical expulsive therapy in the management of distal ureteral stones: a randomized controlled study
}

\author{
Albert AS ${ }^{1}$, Santosh R. Pillai ${ }^{2}$, Anila Mary ${ }^{1}$, Rajeev Aravindakshan ${ }^{3}$ \\ ${ }^{1}$ Department of Urology, ${ }^{2}$ Department of Pharmacology, ${ }^{3}$ Department of Community Medicine, Pushpagiri Medical \\ College, Tiruvalla, Kerala, India \\ Received: 11 December 2015 \\ Revised: 10 January 2016 \\ Accepted: 04 February 2016 \\ *Correspondence: \\ Dr. Santosh Pillai, \\ E-mail: drsantosh74@gmail.com \\ Copyright: (C) the author(s), publisher and licensee Medip Academy. This is an open-access article distributed under \\ the terms of the Creative Commons Attribution Non-Commercial License, which permits unrestricted non-commercial \\ use, distribution, and reproduction in any medium, provided the original work is properly cited.
}

\begin{abstract}
Background: Alpha blockers are being commonly used as adjuvants in the medical management for the expulsion of ureteral stones. The present randomized study aims to evaluate the efficacy of Tamsulosin and Silodosin as medical therapy in the management of symptomatic distal ureteral stones.

Methods: In this randomized control study the 120 patients enrolled were allotted to three groups. Patients in group 1 received tablet Tamsulosin $0.4 \mathrm{mg} /$ day, group 2 received tablet Silodosin $8 \mathrm{mg} /$ day and group 3 served as the control group. Parameters noted were the blood pressure, stone position (\% of expulsion in each group), adverse events noted and number of hospital visits. All patients were followed up weekly for a period of 28 days.

Results: Study showed that both Tamsulosin (80\% success) and Silodosin (85\%success rate) are equally efficacious when compared to the control group. Group 1 and Group 2 required less of pain killers and also had less frequent hospital admissions due to painful episodes as compared to the control group. Usual adverse reaction seen with alpha blockers like orthostatic hypotension and retrograde ejaculation were reported by some subjects in the test groups. Incidence of retrograde ejaculation was found to be more with the Silodosin group.

Conclusions: Both the drugs appear to be effective in the medical management of distal ureteral stones. But Tamsulosin scores over Silodosin as it's well tolerated and with good stone expulsion rates.
\end{abstract}

Keywords: Tamsulosin, Silodosin, Distal ureteral stones

\section{INTRODUCTION}

Urolithiasis is a significant and worldwide health problem. Ureteral stones account for approximately $20 \%$ of urolithiasis cases. $70 \%$ of those cases are with location of stone in the distal $1 / 3^{\text {rd }}$ of ureter hence known as Distal Ureteral Stones (DUS) or Lower Ureteral Stones (LUS). Recently certain drugs have been used as supplement for observation in an effort to improve spontaneous stone expulsion. Tamsulosin and Silodosin are such selective alpha-blockers which act by relaxing the ureteral smooth muscles, richly innervated by alpha-adrenergic receptors. $^{1-4}$
Silodosin is a highly selective alpha 1A adrenoceptor blocker. Medical Expulsive Therapy (MET) is an excellent treatment modality in appropriately selected patients. Evidence suggests that MET can decrease colic events, narcotic usage and re-visits. MET also reduces unnecessary surgeries and associated risks thereby reducing cost of treatment. Despite the evidence, MET remains underutilized as a treatment modality. Factors influencing the spontaneous passage of ureteral stones are stone size, configuration, location, smooth muscle spasm, sub mucosal edema, and anatomy of lower ureter. We evaluated the efficacy of Tamsulosin and Silodosin as the medical treatment of symptomatic uncomplicated distal 
ureteral stones in our center during the period of December 2013 to June 2015 . $^{5-8}$

\section{METHODS}

This was a randomized controlled prospective study to determine the efficacy of tamsulosin and silodosin as adjunctive medical therapy to increase the stone expulsion rate in the distal ureteral calculus of size less than or equal to $10 \mathrm{~mm}$. Out of the 120 patients included in the study, patients were divided randomly into three groups of 40 patients. Patients in group 1 received tablet tamsulosin $0.4 \mathrm{mg} /$ day, group 2 received tablet Silodosin $8 \mathrm{mg} /$ day and group 3 served as the control group. All the three groups of patients were given Diclofenac sodium 50 to $100 \mathrm{mg}$ as the pain relieving agent as when demanded. The patients' blood pressure, stone position, any adverse events and the number of revisits and hospital admissions were assessed and recorded. Patients were followed up weekly, and continued until the stone was expelled, up to a period of 28 days. Failed cases were subjected to surgical intervention after 28 days.

\section{Exclusion criteria}

- Patients with urinary tract infections.

- Patients having previous surgery on ipsilateral ureter.

- Bilateral ureteral calculus.

- Multiple stones.

- Solitary kidney.

- Patients intolerant or hypersensitive to alpha blockers.

- Patients contra-indicated for NSAIDs.

- Patients with renal insufficiency.

- Pregnant and lactating women

Study was approved by the ethical committee of the institute. Patients were followed up weekly up to 28 days. History of stone passage, number of pain attacks, and adverse events any during the course of therapy were recorded. They were followed up with routine urine examinations, kidney function tests and X-Ray KUB film, ultrasonography and in doubtful cases CT. They were advised to watch for stone expulsion. At the end the study, abdominal CT scan was repeated for confirmation of stone expulsion. Patients underwent ureteroscopic stone removal for persistent stones after 28 days. Patients having uncontrolled pain were re-admitted for injectable analgesics and oral medication were continued. The blood pressure, stone position on imaging, number of pain attacks, time taken for stone expulsion, hospital readmissions and adverse events were recorded.

\section{RESULTS}

The comparison of tamsulosin and silodosin in the management of ureteral calculi has shown that both drugs are equally effective in the management of DUS (Table 1). Tamsulosin group of patients showed $80 \%$ success and silodosin group showed $85 \%$ success, when compared to the control group which had only $37 \%$ success in 28 days. The need for analgesics was reduced in the first two groups and had significant less hospital readmission rate, when compared to the control group. Frequency of pain attacks was also reduced in the first two groups. Expulsion time was very much reduced in the first two groups. It is difficult to assess whether the longer stone free period is because of rapid expulsion of stones or due to blockage of c-fiber, responsible for decreasing analgesic requirement.

Alpha receptor blocker related side effects were observed in group 1 and 2 when compared to the control group. Major adverse events were orthostatic hypotension and retrograde ejaculation. Three patients in group 1 and 5 patients in group 2 reported with orthostatic hypotension. 8 patients in group 1 and 5 patients in group 2 complained of retrograde ejaculation. But none of the patients in groups 1 and 2 discontinued the treatment due to adverse events. Group 3 patients didn't have any of these complications mentioned. Upper GI problem secondary to diclofenac sodium ingestion was seen in three groups though more frequent in the control group.

Table 1: Comparison of the different variables in the three groups.

\begin{tabular}{|lllll|}
\hline Variables & Group $\mathbf{1} \mathbf{n = 4 0}$ & Group $\mathbf{2} \mathbf{n = 4 0}$ & Group $\mathbf{3} \mathbf{n = 4 0}$ & P-value \\
\hline Male: Female & $28: 12$ & $32: 8$ & $30: 10$ & 0.5857 \\
\hline Mean age (years) & $35 \pm 8.5$ & $32 \pm 7.5$ & $34 \pm 8.5$ & 0.2520 \\
\hline Stone size (mm) & $7 \pm 2$ & $7 \pm 1.5$ & $6.8 \pm 1.8$ & 0.8451 \\
\hline Efficacy Measures & & & & \\
\hline Stone expulsion: $n(\%)$ & $32(80)$ & $34(85)$ & $15(37)$ & $<0.0001^{*}$ \\
\hline Average duration of stone expulsion (days) & $12 \pm 6.5$ & $12 \pm 7$ & $20 \pm 7.5$ & $<0.0001^{*}$ \\
\hline Average No. of episodes of pain & $3.1 \pm 1$ & $2.8 \pm 1.8$ & $4.3 \pm 1.8$ & $0.0001^{*}$ \\
\hline Revisits / readmissions & 4 & 5 & 20 & $<0.0001^{*}$ \\
\hline Major adverse events & & & 0 & 0.0785 \\
\hline No. of cases : Orthostatic hypotension & 3 & 5 & 0 & $0.0146^{*}$ \\
\hline No. of cases : Retrograde ejaculation & 8 & 5 & 10 & 0.0526 \\
\hline No. of cases : Dyspepsia & 3 & 4 & & \\
\hline
\end{tabular}

$\mathrm{P}<0.05$ statistically significant 


\section{DISCUSSION}

Ureteral colic, which is mainly due to urolithiasis, represents $1-2 \%$ of the hospital emergency admissions. There has been a significant improvement in the medical management of the ureteric calculi with the introduction of effective medical therapeutic agent in the market. ${ }^{9}$

Malan et al first demonstrated the presence of alpha adrenergic receptors in the lumen ureter in 1970. Characteristic distribution of alpha one receptor subtypes in distal, middle and proximal segments is alpha $1 \mathrm{~d}$, alpha 1a, and alpha $1 \mathrm{~b}$. Alpha $1 \mathrm{~d}$ is the most common receptor present in all portions of ureter. It has the strongest effect on the contraction of distal ureter and bladder detrusor, especially for the ureter, bladder wall section and therefore plays an important role in the distal detrusor. Alpha 1 receptor blockers relax ureteral smooth muscles, reduces peristaltic frequency and amplitude, decreases the intraluminal pressure of the ureter, and enhances transportation capability and passage of urine. Moreover they enhance the gradient surrounding the calculi by increasing the pressure above the calculi, relaxes smooth muscles of the bladder neck and urethra and finally the thrust to expel the urine. Alpha receptor blockers can also prevent renal colic events during the process of stone expulsion. ${ }^{10-13}$

JH Furyk et al no benefit overall of $0.4 \mathrm{mg}$ of tamsulosin daily for patients with distal ureteric calculi less than or equal to $10 \mathrm{~mm}$ in terms of spontaneous passage, time to stone passage, pain, or analgesia requirements. R L Sur et al showed in a multi centric study that silodosin was found to be well tolerated and beneficial in facilitating the passage of distal ureteral stones, warranting additional future studies on distal stone elimination. ${ }^{14-16}$

\section{CONCLUSION}

Both tamsulosin and silodosin were equally effective in MET of distal ureteral calculi. But the higher rate of retrograde ejaculation in the Silodosin group makes it less attractive in males in the sexually active age, who are prone to ureteral calculi. So in our study, tamsulosin was found to be more acceptable for MET of distal ureteric calculi, with a higher rate of stone expulsion and less adverse events. Cost of therapy is less in tamsulosin group when compared with silodosin.

Lower doses of analgesic requirement, fewer emergency visits, less need for hospitalization for recurrent pain and cost-effective treatment when compared to surgical intervention with its inherent associated complications, points to MET as the treatment of choice for uncomplicated distal ureteral calculi.

Funding: No funding sources Conflict of interest: None declared

Ethical approval: The study was approved by the institutional ethics committee

\section{REFERENCES}

1. Hesse A, Brändle E, Wilbert D, Köhrmann KU, Alken P. Study on the prevalence and incidence of urolithiasis in Germany. European Urology. 2003;44(6):709-13.

2. Wolf JS. Treatment Selection and Outcomes: Ureteral Calculi, Urologic Clinics of North America. 2007;34(3):421-30.

3. Gupta S, Lodh B, Singh AK, Somarendra K, Meitei KS, Singh SR. comparing the efficacy of tamsulosin and silodosin in the medical expulsion therapy for ureteral calculi. Journal of clinical and diagnostic research : JCDR. 2013;7(8):1672-4.

4. Andersson KE and Gratzke C. Pharmacology of $\alpha 1$ adrenoceptor antagonists in the lower urinary tract and central nervous system. Nature reviews urology. 2007;4(7):368-78.

5. Marks LS, Gittelman MC, Hill LA, Volinn W, Hoel G. Rapid efficacy of the highly selective $\alpha 1 \mathrm{a}-$ adrenoceptor antagonist silodosin in men with signs and symptoms of benign prostatic hyperplasia: pooled results of 2 phase 3 studies. The journal of urology. 2009;181(6):2634-40.

6. Brede C, Hollingsworth JM, Faerber GJ, Taylor JS, Wolf JS. Medical expulsive therapy for ureteral calculi in the real world: targeted education increases use and improves patient outcome. The journal of urology. 2010;183(2):585-9.

7. Hollingsworth JM, Rogers MAM, Kaufman SR, Bradford TJ, Saint S, Wei JT, et al. Medical therapy to facilitate urinary stone passage: a meta-analysis, The Lancet. 2006;368(9542):1171-9.

8. Yilmaz E, Batislam E, Basar MM, Tuglu D, Ferhat $\mathrm{M}$, Basar $\mathrm{H}$. The comparison and efficacy of 3 different $\alpha 1$-adrenergic blockers for distal ureteral stones. The journal of urology. 2005;173(6):2010-2.

9. Cervellin G, Comelli I, Comelli D, Cortellini P, Lippi G, Meschi T, et al. Regional short-term climate variations influence on the number of visits for renal colic in a large urban emergency department: results of a 7-year survey. Internal and emergency medicine. 2011;6(2):141-7.

10. López M, Hoppe B. History, epidemiology and regional diversities of urolithiasis. Pediatric Nephrology. 2010;25(1):49-59.

11. Park HK, Choi EY, Jeong BC, Kim HH, Kim BK. Localizations and expressions of $\alpha-1 \mathrm{~A}, \alpha-1 \mathrm{~B}$ and $\alpha$ 1D adrenoceptors in human ureter. Urological research. 2007;35(6):325-9.

12. Danuser H, Weiss R, Abel D, Walter B, Scholtysik G, Mettler D, et al. Systemic and topical drug administration in the pig ureter: effect of phosphodiesterase inhibitors $\alpha 1, \quad \beta$ and $\beta 2$ adrenergic receptor agonists and antagonists on the frequency and amplitude of ureteral contractions. The journal of urology. 2001;166(2):714-20.

13. Dellabella M, Milanese G, Muzzonigro G. Randomized trial of the efficacy of tamsulosin, nifedipine and phloroglucinol in medical expulsive 
therapy for distal ureteral calculi. The journal of urology. 2005;174(1):167-72.

14. Furyk JS, Chu K, Banks C, Greenslade J, Keijzers $\mathrm{G}$, Thom O, et al. Distal ureteric stones and tamsulosin: a double-blind, placebo-controlled, randomized, multicenter trial. Annals of emergency medicine. 2016;67(1):86-95.

15. Sur RL, Shore N, L'Esperance J, Knudsen B, Gupta $\mathrm{M}$, Olsen $\mathrm{S}$ et al. Silodosin to facilitate passage of ureteral stones: a multi-institutional, randomized, double-blinded, placebo-controlled trial. European urology. 2015;67(5):959-64.

16. Ljunghall S, Hedstrand H. Epidemiology of renal stones in a middle aged male population. Acta Medica Scandinavica.1975;197(1-6):439-45.

Cite this article as: Albert AS, Pillai SR, Mary A, Aravindakshan R. Efficacy of tamsulosin and silodosin as medical expulsive therapy in the management of distal ureteral stones: a randomized controlled study. Int Surg J 2016;3:578-81. 